\title{
Characterization of cuticular hydrocarbons according to colony duties in the stingless bee Tetragonisca angustula
}

\author{
María Sol Balbuena $^{1,2}$, Andrés GonZÁLEZ ${ }^{3}$, Walter M. Farina ${ }^{1,2}$ \\ ${ }^{1}$ Laboratorio de Insectos Sociales. Departamento de Biodiversidad y Biología Experimental, Facultad de Ciencias \\ Exactas y Naturales, Universidad de Buenos Aires, Pabellón II, Ciudad Universitaria, C1428EHA, Buenos Aires, \\ Argentina \\ ${ }^{2}$ Instituto de Fisiología, Biología Molecular y Neurociencias (IFIBYNE), CONICET-Universidad de Buenos Aires, \\ Buenos Aires, Argentina \\ ${ }^{3}$ Laboratorio de Ecología Química, Facultad de Química, Universidad de la República, Gral. Flores 2124, CP 11800, \\ Montevideo, Uruguay
}

Received 11 May 2017 - Revised 28 July 2017 - Accepted 14 August 2017

\begin{abstract}
In social insects, task-related recognition plays an important role in the coordination and cohesion between members of the colony. Tetragonisca angustula is an eusocial stingless bee that presents a sophisticated system of defense involving two complementary groups of guards: hovering and standing guards. We identified, quantified, and compared the cuticular compounds of worker bees captured within the nest, and bees performing tasks outside: foragers and guards. In addition to cuticular hydrocarbons (CHCs), we identified abundant di- and triterpenes. Among the CHCs, we found a mixture of n-alkanes, methyl-branched alkanes, alkenes, and alkadienes. Significant differences in the relative abundance of CHCs between behavioral groups were found. Particularly, guards present high amounts of branched alkanes relative to nest bees and foragers. Differential CHC profiles associated with behavioral groups could imply a mechanism for caste recognition.
\end{abstract}

\section{stingless bees / Tetragonisca angustula / cuticular hydrocarbons / task-related recognition}

\section{INTRODUCTION}

In ants, wasps, termites, and bees, cuticular hydrocarbons (CHCs) have been reported as relevant cues involved in the discrimination between nestmate and non-nestmate (Howard and Blomquist 2005). Kather et al. (2011) have shown that Apis mellifera task groups differ in their cuticular chemical profiles, especially in the composition of n-alkanes and alkenes. In particular, task groups vary in alkene profile, suggesting that alkenes could function as intracolonial

Corresponding author: M. Balbuena, msbalbuena@bg.fcen.uba.ar

Andrés González and Walter M. Farina are joint senior co-authors.

Manuscript Editor: Monique Gauthier recognition compounds. In assays where the cuticular hydrocarbon profile was manipulated through supplementation of alkanes or alkenes naturally present on the cuticle, Dani et al. (2005) found that honeybees treated with alkenes were attacked more intensively by their nestmates than honeybees treated with alkanes. Similar results were found in the paper wasp Polistes dominulus; individuals treated with alkenes or methyl-branched alkanes were attacked by their nestmates, while those supplied with lineal alkanes were not (Dani et al. 2001). In the carpenter ant, Camponotus herculeanus, the presence of an additional dimethylated alkane was effective to elicit the aggressive behavior of nestmates towards the treated ant (Guerrieri et al. 2009). These studies show that modifications of the cuticular chemical profile have an effect on rejection or acceptance by nestmates. 
Despite their considerable diversity and important ecological role as pollinators, the knowledge of CHCs and their function in stingless bees (Meliponini) is still limited. It has been shown that bees from different colonies of Scaptatotrigona bipuncatata present differences in their $\mathrm{CHC}$ profile (Jungnickel et al. 2004). Buchwald and Breed (2005) showed that alkanes and alkenes, among other compounds, are used in nestmate recognition in the stingless bee Trigona fulviventris. In the same line, guard bees of Frieseomelitta varia were found to recognize cuticular chemical similarities and dissimilarities, which correlated with the level of acceptance or aggressive behavior towards nestmates and non-nestmates (Nunes et al. 2008). In Schwarziana quadripunctata, differences were reported between bees, not only from different colonies but also between workers of different age and between different reproductive castes (Nunes et al. 2009). Similar results were found in Melipona marginata and Melipona quadrifasciata, in which workers present specific cuticular profiles according to the task group they belong to (Ferreira-Caliman et al. 2010; Cruz-Landim et al. 2012). Moreover, Borges et al. (2012) found differences in the cuticular profiles of males, workers, and virgin queens of $M$. quadrifasciata among individuals of different phenotypes, and in M. bicolor the composition of $\mathrm{CHCs}$ varied between and within the castes and sexes as well (Abdalla et al. 2003).

Our study subject, Tetragonisca angustula (Latreille), is a small eusocial stingless bee (4$5 \mathrm{~mm}$ ) which presents a wide Neotropical distribution. This bee is found from Mexico to the northern part of Argentina (Camargo and Pedro 1992; Moure 2008; Yáñez-Ordónez et al. 2008) and is considered one of the most important native pollinator agents in the region. T. angustula nests can be found in tree cavities, in the ground, or in almost any small artificial cavity, and can be recognized by a characteristic wax entrance tube (Michener 2007). As eusocial insects, they live in colonies of 2000-5000 individuals (Zamudio and Alvarez 2016) and present division of labor among workers. Early in adult life, worker bees perform tasks inside the nest (building or inspection of brood cells, waste and resin manipulation), and at the age of 14-21 days old, they start leaving the nest to perform outside task as foraging or guarding (Hammel et al. 2016). The age at which foragers and guards perform a particular task within the nest is highly correlated, but guards transitioned faster from one duty to the next: they are, on average, 2 days younger when they performed a task (Hammel et al. 2016). Likewise, Segers and co-workers (2015) showed that guard determination is based on nutritional factors: guard-sized workers emerge from brood cells containing high amounts of larval food. In this sense, outside tasks are performed toward the end of life, in which guarding will be performed by large workers and foraging by small workers (Grüter et al. 2012), although not all large workers become guards (Segers et al. 2015).

Of note, $T$. angustula presents a peculiar and sophisticated defense system, which involves two complementary types of nest entrance guards (Kärcher and Ratnieks 2009): hovering guards, which are suspended in the air close to the nest entrance, and standing guards, which stand on the inner or outer surface of the wax entrance tube. Both types of guard bees spend a considerable amount of time performing their specific tasks (Kelber and Zeil 1997; Grüter et al. 2011) and, as we mentioned above, they show morphological differences with respect to forager bees: they are bigger and present different shape (namely larger hind legs and relatively smaller heads for their body weight). Hence, they have been regarded as a worker subcaste (Grüter et al. 2012), which in turn present division of labor between standing and hovering guard bees (Grüter et al. 2011).

Although there are many studies related with the biology of $T$. angustula, including their division of labor (Grosso and Bego 2002; Grüter et al. 2012; Hammel et al. 2016), guarding behavior, and nest defense (Kärcher and Ratnieks 2009; van Zweden et al. 2011), there have been no studies on their CHCs and their potential as casterecognition cues. Here, we present the first comparative study of $\mathrm{CHC}$ profiles of different worker 
castes of T. angustula: nest bees, foragers, and both types of guard bees.

\section{MATERIALS AND METHODS}

Study site and animals Two colonies of the stingless bee $T$. angustula with a queen, brood, and reserves were used. Wooden boxes containing each about 4000 worker bees remained open and the bees could forage freely outside. Foragers from both colonies had access to a natural environment containing wild flowers. Experiments were performed in summer 2015 at the Experimental Field of Universidad de Buenos Aires (Argentina, $34^{\circ}$ $\left.32^{\prime} \mathrm{S}, 58^{\circ} 26^{\prime} \mathrm{W}\right)$. Chemical analyses of cuticular extracts were carried out at the Universidad de la República in Montevideo, Uruguay.

Experimental procedure Four groups of worker bees were captured from the two colonies. We identified the four types of workers according to their behavior. Forager bees were trained to an artificial feeder containing unscented $50 \% \mathrm{w} / \mathrm{w}$ sucrose solution, located $2 \mathrm{~m}$ from the nest entrance. Foragers were captured at the feeder, before they took off to return to the nest. Guard bees were collected directly from the entrance tube (standing guards) or while hovering in front of the tube (hovering guards). The fourth group was collected from inside the nest (nest bees).

Captured bees were immediately chilled in a freezer for $3 \mathrm{~min}$ and immersed in dichloromethane to extract cuticular compounds (see below). For both colonies, we analyzed ten samples per bee group treatment, except for foragers for which nine samples were analyzed.

Cuticular chemistry Cuticular compounds were extracted in dichloromethane (DCM) at room temperature. In order to detect and quantify less abundant CHCs such as methyl-branched alkanes or alkadienes, the bees were extracted in pooled samples consisting of groups of three bees. In all cases, extractions were done in 1-dram screw-cap vials with $0.5 \mathrm{~mL}$ of DCM and $20 \mu \mathrm{L}$ of eicosane $(0.3 \mathrm{mg} / \mathrm{mL}$ in hexane) as internal standard (IS). After 1 min of vortexing, the solvent was removed and the extraction procedure was repeated twice without the addition of the IS. Finally, the three portions of the extract were joined (1.5 $\mathrm{mL}$ total) and concentrated to $0.5 \mathrm{~mL}$ under a stream of nitrogen for further analysis.

Chemical analyses were done by gas chromatography coupled to mass spectrometry (GC-MS), using a Shimadzu QP-2010 GC-MS equipped with a RTX-5MS column (Restek, USA) $(30 \mathrm{~m} \times 0.25 \mathrm{~mm}, 0.25 \mu \mathrm{m})$, and operated with a constant carrier flow of $1 \mathrm{~mL} / \mathrm{min}(\mathrm{He})$. The temperature of the $\mathrm{GC}$ oven was programmed from $120{ }^{\circ} \mathrm{C}(1 \mathrm{~min})$ to $200{ }^{\circ} \mathrm{C}$ at $10{ }^{\circ} \mathrm{C} / \mathrm{min}$, then raised to $310^{\circ} \mathrm{C}$ at $5{ }^{\circ} \mathrm{C} / \mathrm{min}$, and held for $4 \mathrm{~min}$ at $310^{\circ} \mathrm{C}$. The injector temperature was $250{ }^{\circ} \mathrm{C}$ and the interphase temperature $310^{\circ} \mathrm{C}$. Injection $(1 \mu \mathrm{L})$ was in the splitless mode (sampling time $1 \mathrm{~min}$ ), and mass spectra were acquired from $\mathrm{m} / \mathrm{z}$ 40 to 500 .

Statistical analysis For each sample, peak areas higher than $0.1 \%$ of the total ion chromatogram (TIC) were considered for the analysis (excluding the area of the IS). In addition, compounds were excluded if they were not present in at least three samples of any given bee group (nest bees, foragers, standing, and hovering guards).

The net amounts of individual CHCs (in microgram equivalents of IS) in the cuticular extracts of the four bee groups were first subject to a principal component analysis (PCA) (Quinn and Keough 2002).

In addition, $\mathrm{CHCs}$ were grouped as n-alkanes, branched alkanes, and alkenes, and the added amounts for each group were compared among bee groups using a generalized linear model (GLM) with Gaussian error distribution. The models included colony and bee group as fixed factors. The models were fitted in R 3.3.1 (R Development Core Team 2016) using the GLM function of the R-package MASS (Venables and Ripley 2002). Tukey HSD contrasts with adjusted $p$ values (Bonferroni) were performed as post hoc comparisons, using the glht function of the Rpackage multcomp (Hothorn et al. 2008).

\section{RESULTS}

GC-MS analyses of the surface extracts showed consistent results among the different 
bee samples, with no noticeable qualitative differences but distinct quantitative variation among T. angustula worker subcastes. About 40 peaks were consistently found in the GC-MS analyses, most of them corresponding to CHCs (1-19 in Figure 1). Peaks corresponding to compounds other than CHCs were only tentatively identified and not considered any further in this study, since we were interested in the CHC profiles of the different bee groups. Of these non-CHCs, two small peaks between 14 and 15 min (Figure 1, unlabeled) were tentatively identified as linoleic and oleic acids from their mass spectra and retention indices. While our extraction procedure targeted surface cuticular compounds, small amounts of fatty acids may be expected as they are quite soluble in dichloromethane. Other unlabeled peaks between 15 and 20 min (Figure 1) were tentatively grouped as diterpenes from the consistent suggestions of the mass spectral library. More abundant peaks, collectively labeled as triterpenes (Figure 1), were also assigned on a tentative basis from the suggestions of the mass spectral library, which found as best matches for all peaks between 30 and $34 \mathrm{~min}$ on different triterpenes of the lupane or lanostane types.
We concentrated our efforts in cuticular hydrocarbons for quantitative analysis and identification. We found $19 \mathrm{CHCs}$, including normal saturated alkanes, minor amounts of methyl-branched alkanes, and mono- and di-unsaturated unbranched alkenes (Figure 1; Table I). The CHCs were identified on the basis of their mass spectra and retention indices in comparison with those of databases (Linstrom and Mallard 2005; Adams 2007; El-Sayed 2014).

The chromatograms of cuticular extracts were dominated by n-alkanes $\left(\mathrm{C}_{25}\right.$ and $\mathrm{C}_{27} ; 5$ and 10 in Figure 1), with lower amounts of alkenes and methyl-branched alkanes. The net amount of each $\mathrm{CHC}$ was calculated from the TIC peak areas as microgram equivalents of internal standard per bee, as shown in Table I for the different task groups, namely nest bees, foragers, and guards (standing and hovering).

We performed a PCA analysis of $\mathrm{CHC}$ net amounts for both colonies separately, resulting in two principal components (PC) for each colony, which represented $42.30 \%$ (PC1) and $27.16 \%$ (PC2) of the overall variance for colony 1 (Figure 2a), and $46.70 \%$ (PC1) and $31.74 \%$ (PC2) for colony 2 (Figure 2b). We found

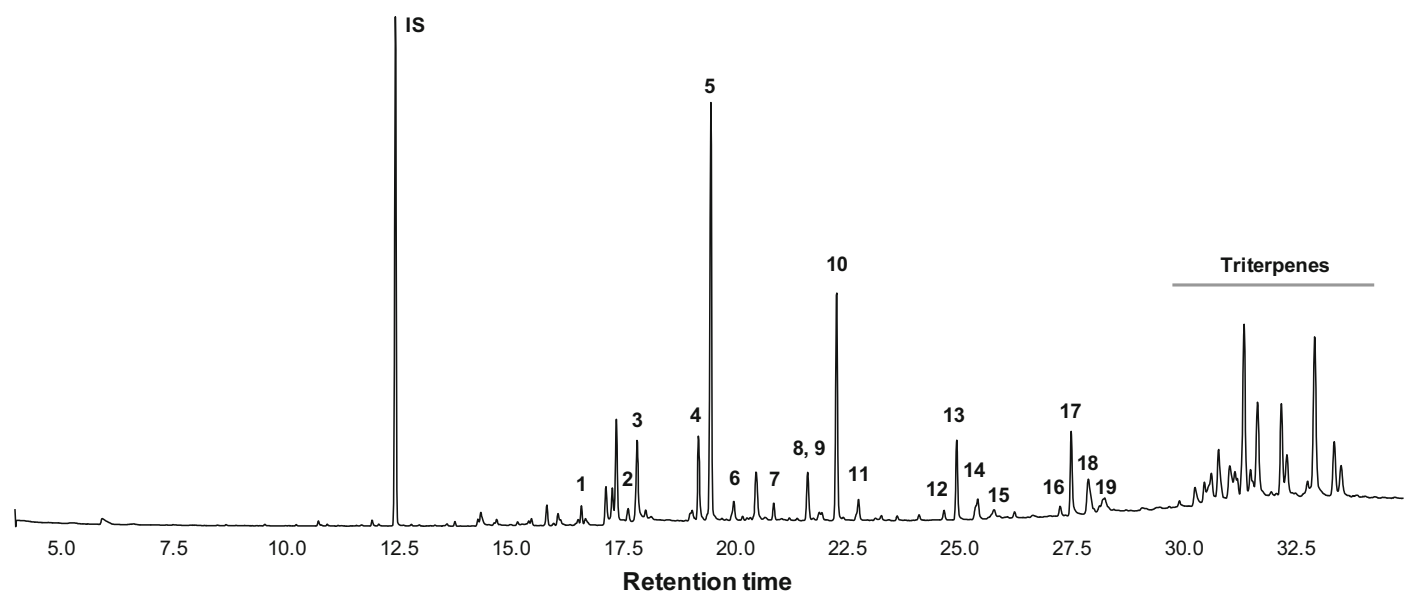

Figure 1. Typical total ion chromatogram of cuticular extracts of Tetragonisca angustula. Peaks 1 through 19 correspond to cuticular hydrocarbons. See text for GC-MS conditions and Table I for quantitative data. 1: ntricosane, 2: Me-tricosane, 3: n-tetracosane, 4: Me-tetracosane, 5: n-pentacosane, 6: 9-Me-pentacosane, 7: nhexacosane, 8: X,Y-heptacosadiene, 9: X-heptacosene, 10: n-heptacosane, 11: 9-Me-heptacosane, 12: Xnonacosene, 13: n-nonacosane, 14: 9-Me-nonacosane, 15: Me-nonacosane, 16: X-hentriacontene, 17: nhentriacontane, 18: Me-hentriacontane, 19: Me-hentriacontane. IS internal standard, n-eicosane; $X$ and $Y$ indicate unknown position of the methyl group or double bond. 


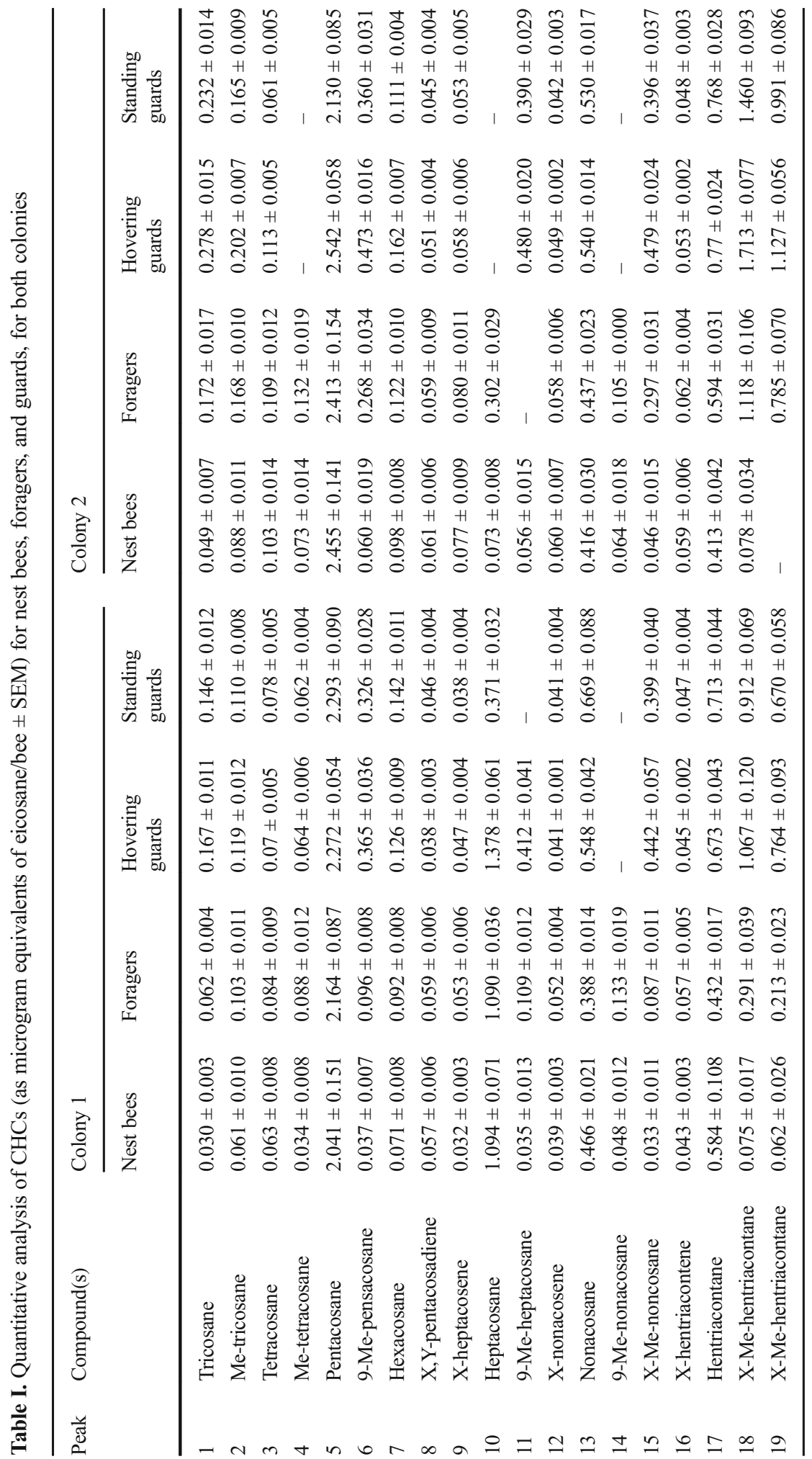



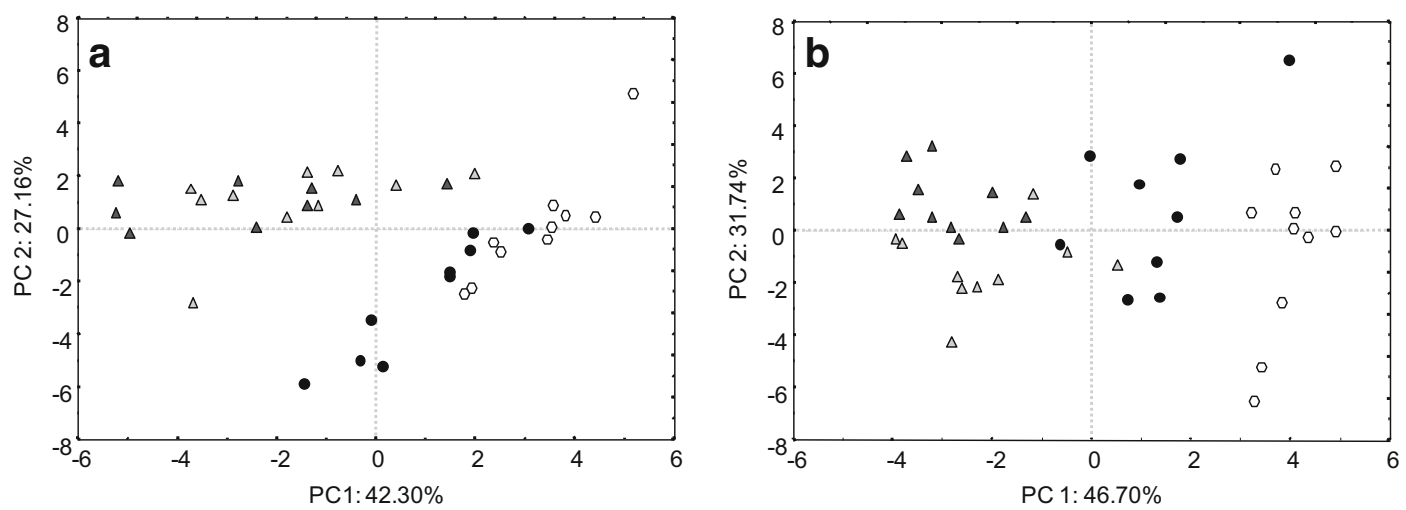

Figure 2. Relationship between cuticular hydrocarbons and behavioral worker groups. Scores plot showing the relationship of cuticular hydrocarbons extracted from bees from different colonies and task groups (a Colony 1, b Colony 2). Foragers: black circles, nest bees: white hexagons, hovering guards: dark gray triangles, standing guards: light gray triangles). For both colonies $N=10$ samples per bee group, except foragers with $N=9$ samples. The two main principal components (PC) account for $42.30 \%$ (PC1) and $27.16 \%$ (PC2) of the overall data variance for colony 1 , and $46.70 \%$ (PC1) and $31.74 \%$ (PC2) for colony 2.

significant differences among bee groups in both colonies. In the case of colony 1 , both principal components segregated the bee groups as guards (hovering and standing) vs. foragers and nest bees. While in colony 2 , the major contributing component (PC1) clearly segregated the same task groups.

To further analyze which compounds were causing these overall differences, we grouped CHCs into n-alkanes, branched alkanes, and alkenes, and compared their amounts in the four behavioral bee groups (nest bees, foragers, standing, and hovering guards). For colony 1 , we found significant differences among the groups in linear and branched alkanes, but not in the amounts of alkenes (Figure 3, top panels. GLM; n-alkanes: $F_{3,34}=4.675, P=0.008$; branched alkanes: $F_{3,34}=53.594, P<0.001 ;$ alkenes: $\left.F_{3,34}=2.891, P=0.05\right)$. Hovering guards presented higher amounts of linear alkanes, while the other three groups of bees showed similar amounts (Figure 3a; see Table II for all Tukey HSD contrasts). When comparing the amounts of branched alkanes, we found that both types of guards presented higher amounts than foragers and nest bees, with no significant differences between standing and hovering guards (Figure $3 b$ ).

For colony 2, the amounts of n-alkanes only differed between nest bees and hovering guards
(Figure 3d; GLM: $F_{3,35}=4.349, P=0.010$ ). As found in colony 1 , the amounts of branched alkanes between standing and hovering guards were similar, and both were higher than in foragers and nest bees (Figure $3 \mathrm{e} ; F_{3,35}=80.49, P<0.001$ ). When we analyzed the amounts of alkenes, we only found a significant difference between nest bees and standing guards (Figure 3f; GLM: $\left.F_{3,35}=3.489, P=0.026\right)$.

\section{DISCUSSION}

Our results demonstrate that there is a variation in the cuticular hydrocarbon composition of T. angustula workers in relation to their behavioral duty. This variation seems to be more related to quantitative differences rather than to qualitative variations, because no compound occurred exclusively in the cuticle of any worker group. We found that guards differ from foragers and nest bees in both of the colonies included in our study: nest bees present low amounts of total alkanes relative to the groups performing tasks outside, and guards present high amounts of branched saturated hydrocarbons compared to both foragers and nest bees. These results are in line with studies conducted in ants, which show that within a species, differences in the cuticular chemical profile are usually quantitative rather than qualitative, 

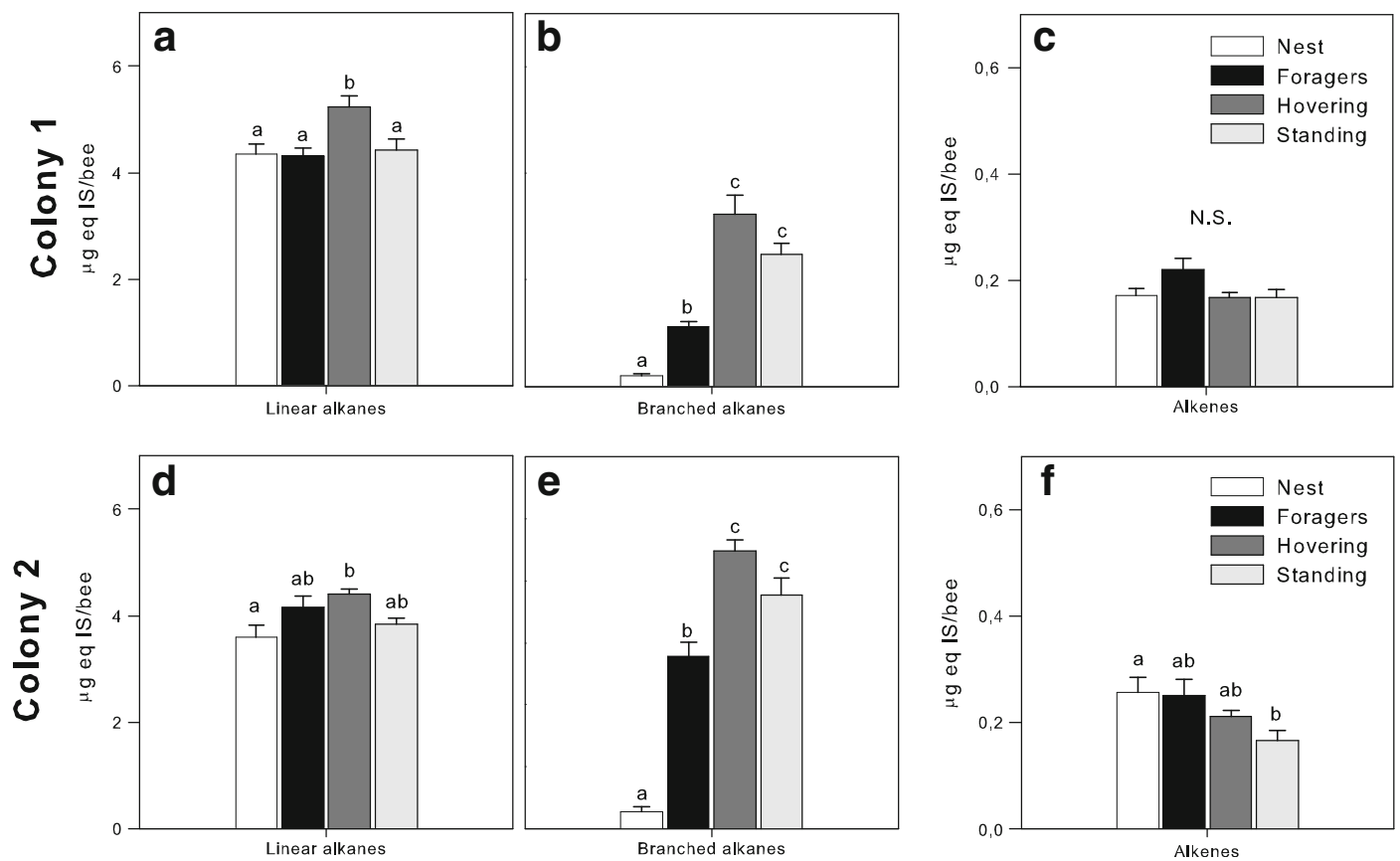

Figure 3. Hydrocarbon amounts extracted from the four behavioral worker groups (colony 1: top panels, colony 2: bottom panels). Net hydrocarbon amounts (microgram equivalents of IS per bee) grouped as linear alkanes (a, d ), branched alkanes $(\mathbf{b}, \mathbf{e})$, or alkenes $(\mathbf{c}, \mathbf{f})$ for nest bees (white bars), foragers (black bars), hovering guards (dark gray bars) and standing guards (light bars). Error bars represent standard error of the mean. Different letters indicate significant differences $(P<0.05)$. N.S. not significant $(P>0.05)$.

with non-nestmates conspecifics presenting the same compounds in their cuticular profiles, but in different relative proportions (d'Ettorre and Lenoir 2010). Likewise, Lorenzi et al. (2004) reported that after the emergence, the cuticular profile of young social wasps Polistes dominulus presents an increase of the total quantities of CHCs. In particular, the relative amounts of branched alkanes increase when compared with linear alkanes and alkenes.

In addition to the $19 \mathrm{CHCs}$ characterized in this study, we found high-molecular weight terpenes that remain to be identified. The presence of these compounds in our samples is not unexpected since terpenoids are originally acquired from plant resins, a rich source of higher terpenes (Velikova et al. 2000; Sawaya et al. 2006). In fact, stingless bees are known to collect and use resins as building material for nest construction and defense (Michener 1974; Roubik 2006; Zamudio and Alvarez 2016). Moreover, Leonhardt et al. (2009) have reported that some stingless bee species incorporate resin compounds in their own cuticular profile. They found that seven Southeast-Asian paleotropical stingless bee species differed in the amounts of mono-, sesqui-, and triterpenes present in their chemical profiles. A proper characterization of diterpenes and triterpenes from $T$. angustula would require bulk extraction and isolation in amounts sufficient for NMR spectroscopy, since these are structurally complex and diverse natural products. These tasks were beyond our current possibilities, but their potential significance as defense compounds, most likely of plant origin, makes them an attractive venue for future research. Whether terpenoids may also play a role as chemical cues for nestmate or caste recognition deserves further studies as well.

T. angustula presents two types of guards which are morphologically different from foragers (Grüter et al. 2012) and can function as two defensive lines at the nest entrance, intercepting and attacking allo- and conspecific intruders (Wittman 
Table II. Tukey HSD contrasts with adjusted $p$ values (Bonferroni). Post hoc comparisons for all bee groups and both colonies

\begin{tabular}{|c|c|c|c|c|c|c|}
\hline & \multicolumn{2}{|c|}{ Linear alkanes } & \multicolumn{2}{|c|}{ Branched alkanes } & \multicolumn{2}{|l|}{ Alkenes } \\
\hline & $z$ & $P$ & $\mathrm{z}$ & $P$ & $z$ & $P$ \\
\hline \multicolumn{7}{|l|}{ Colony 1} \\
\hline Nest bees vs. foragers & 0.119 & 1.000 & 5.650 & $<0.001$ & - & - \\
\hline Nest bees vs. hovering & -3.319 & 0.010 & 6.545 & $<0.001$ & - & - \\
\hline Nest bees vs. standing & 0.240 & 1.000 & -6.408 & $<0.001$ & - & - \\
\hline Foragers vs. hovering & 3.176 & 0.009 & -4.098 & $<0.001$ & - & - \\
\hline Foragers vs. standing & 0.353 & 1.000 & -3.344 & 0.005 & - & - \\
\hline Hovering vs. standing & -2.905 & 0.022 & 1.269 & 1.000 & - & - \\
\hline \multicolumn{7}{|l|}{ Colony 2} \\
\hline Nest bees vs. foragers & -2.253 & 0.146 & -8.412 & $<0.001$ & 0.160 & 1.000 \\
\hline Nest bees vs. hovering & -3.375 & 0.004 & -14.519 & $<0.001$ & 1.436 & 0.906 \\
\hline Nest bees vs. standing & 0.997 & 1.000 & 12.050 & $<0.001$ & -2.869 & 0.025 \\
\hline Foragers vs. hovering & 1.033 & 1.000 & 5.720 & $<0.001$ & -1.238 & 1.000 \\
\hline Foragers vs. standing & -1.282 & 1.000 & 3.317 & 0.005 & -2.632 & 0.050 \\
\hline Hovering vs. standing & -2.378 & 0.104 & -2.469 & 0.081 & -1.433 & 0.912 \\
\hline
\end{tabular}

Significance threshold $p=0.05$

1985; van Zweden et al. 2011; Kärcher and Ratnieks 2009; Couvillon et al. 2013). Our results show that they differ not only in their particular behavior and morphology but also by their characteristic cuticular $\mathrm{CHC}$ profiles. We found that the amounts of branched alkanes among standing and hovering guards were similar, and also higher than in foragers and nest bees. These quantitative differences could be related to the fact that both types of guards were described as $30 \%$ heavier than foragers (Grüter et al. 2012); however, we found that only branched alkanes are particularly higher in guards.

Methyl-branched hydrocarbons have been described as species-specific compounds involved in nestmate recognition in ants (Martin and Drijfhout 2009; Guerrieri et al. 2009) and wasps (Dani et al. 2001). In addition to this, van Wilgenburg et al. (2010) have reported that Argentine ants can easily discriminate between compounds bearing moieties as double bond and methyl branches, but cannot discriminate n-alkanes. Thus, it is possible that branched alkanes present in the cuticular profiles of guards are involved in nestmate recognition. Regarding this, Bowden et al. (1994) found that T. angustula guards rarely attack non-nestmate conspecifics. Likewise, Kärcher and Ratnieks (2009) showed that although the level of rejection of conspecific is higher compared to honeybees and other stingless bee species (Downs and Ratnieks 2000; Couvillon and Ratnieks 2008), standing guards of T. angustula allowed entrance to around $10 \%$ of non-nestmates. In this way, branched alkanes present in guards might be detected by nonnestmates before they arrive at the "wrong" nest entrance, and they are detected by guards, thus avoiding being attacked. However, additional studies including the manipulation of these specific compounds are necessary to test if branched alkanes are effectively involved in nestmate recognition.

As it has been reported to the stingless bees Schwarziana quadripunctata (Nunes et al. 2009) and Scaptatotrigona bipuncatata (Jungnickel et al. 2004), we also found small differences between the cuticular chemical profiles of both colonies used. This could be related to varying factors, for example, the material used in the nest (resin, wax), collected food, or queen pheromone (D' ettorre et al. 2006; Couvillon et al. 2007; Couvillon and Ratnieks 2008; Guerrieri et al. 
2009). The nest wax probably homogenizes the colony odor, resulting in a particular chemical profile for each colony that may itself serve as a nest recognition cue by nestmates. Despite these differences, we found a common pattern between the two colonies: CHC profiles of guards differ from foragers and nest bees.

As we mentioned above, we found similar amounts of branched alkanes between both types of guard bees, and higher than foragers and nest bees; thus, these compounds would not only be involved in subcastes recognition, but also they could play a potential role in nestmate recognition, as was described in M. marginata, M. quadrifasciata, and M. bicolor, in which CHC profiles varied between castes, according to the task group they belonged to (Abdalla et al. 2003; Ferreira-Caliman et al. 2010; Cruz-Landim et al. 2012; Borges et al. 2012). In addition, hovering guards presented higher amounts of linear alkanes than nest bees. This could be related to avoiding water loss, since n-alkanes provide better waterproofing than alkenes and branched alkanes of similar size due to their shape (Gibbs and Pomonis 1995). Thus, n-alkanes could have a protective value against dehydration in guard bees that are hovering close to the nest entrance for long time.

Our results suggest that significant differences in the relative proportions of CHCs may play an important role in nestmate and worker group identification according to their behavioral task. In fact, the presence of a differential cuticular hydrocarbon profile among individuals performing different tasks could facilitate the coordination and cohesion of the entire colony.

\section{ACKNOWLEDGMENTS}

We thank Diego Vázquez for helping us with the statistical analysis. This study was partly supported by grants from Agencia Nacional de Promoción Científica y Tecnológica (ANPCYT), Consejo Nacional de Investigaciones Científicas y Técnicas (CONICET), Universidad de Buenos Aires, and Universidad de la República.

Author's contributions MSB, AG, and WMF conceived and designed the experiments. MSB performed the experiments. AG performed chemical analysis. MSB, AG, and
WMF performed data analysis. MSB, AG, and WMF drafted the manuscript. All authors revised and commented on the manuscript.

Caractérisation des hydrocarbones cuticulaires des abeilles sans aiguillon, Tetragonisca angustula, en fonction du rôle des individus dans la colonie

Meliponini / répartition des tâches / reconnaissance des castes / terpènes / alkanes / cuticule

Charakterisierung der kutikulären Kohlenwasserstoffe im Zusammenhang mit den Aufgaben des Bienenvolkes bei der stachellosen Biene Tetragonisca angustula

Stachellose Bienen / Tetragonisca angustula / kutikuläre Kohlenwasserstoffe / arbeitsabhängige Erkennung

\section{REFERENCES}

Abdalla, F.C., Jones, G.R., Morgan, E.D., Cruz-Landim, C. (2003) Comparative study of the cuticular hydrocarbon composition of Melipona bicolor Lepeletier, 1836 (Hymenoptera, Meliponini) workers and queens. Genet. Mol. Res. 2 (2), 191-199

Adams, R.P. (2007) Identification of essential oil components by Gas Chromatography/Mass Spectrometry. Carol Stream: Allured Publishing. 804 p

Borges, A.A., Ferreira-Caliman, M.J., Nascimento, F.S., Campos, L.A.O., Tavares M.G. (2012) Characterization of cuticular hydrocarbons of diploid and haploid males, workers and queens of the stingless bee Melipona quadrifasciata. Insectes Soc., 59 (4), 479486

Bowden, R.M., Garry, M.F., Breed, M.D. (1994) Discrimination of con- and heterospecific bees by Trigona (Tetragonisca) angustula guards. J. Kansas. Entomol. Soc. 67 (1), 137-139

Buchwald, R., Breed, M.D. (2005) Nestmate recognition cues in a stingless bee, Trigona fulviventris. Anim. Behav. 70, 1331-1337

Camargo, J.M.F., Pedro, S.R.M. (1992) Systematics, phylogeny and biogeography of the Meliponinae (Hymenoptera, Apidae): a mini-review. Apidologie 23, 509522

Couvillon, M.J., Ratnieks, F.L.W. (2008) Odour transference in stingless bee marmelada (Frieseomelitta vari $\mathrm{a}$ ) demonstrates that entrance guards use an "undesirableabscent" recognition system. Behav. Ecol. Sociobiol. 62, 1099-1105

Couvillon, M.J., Caple, J.P., Endsor, S.L., Kärcher, M.H., Russell, T.F., Storey, D.E., Ratnieks, F.L.W. (2007) Nest-mate recognition template of guard honeybees 
(Apis mellifera) is modified by wax comb transfer. Biol. Lett. 3, 228-230

Couvillon, M.J., Segers, F.H.I.D., Cooper-Bowman, R., Truslove, G., Nascimento, D.L., Nascimento, F.S, Ratnieks, F.L.W. (2013) Contexts affects nestmate recognition errors in honey bees and stingless bees. J. Exp. Biol. 216, 2411-2418

Cruz-Landim, C., Ferreira-Caliman, M.J., Gracioli-Vitti, L.F., Zucchi, R. (2012) Correlation between mandibular gland secretion and cuticular hydrocarbons in the stingless bee Melipona quadrifasciata. Genet. Mol. Res. 11 (2), 966-977

D' ettorre, P., Wenseleers, T., Dawson, J., Hutchinson, S., Boswell, T., Ratnieks, F.L.W. (2006) Wax combs mediate nestmate recognition by guard honyebees. Anim. Behav. 71, 773-779

d'Ettorre, P., Lenoir, A. (2010)"Nestmate recognition" in Ant Ecology, eds L. Lach, C. Parr, and K. Abbott (Oxford: Oxford University Press), 194-209

Dani, F.R., Jones, G.R., Destri, S., Spencer, S.H., Turillazzi, S. (2001) Deciphering the recognition signature within the cuticular chemical profile of paper wasps. Anim. Behav. 62 , 165-171

Dani, F.R., Jones, G.R., Corsi, S., Beard, R., Pradella, D., Turillazzi, S. (2005) Nestmate recognition cues in the honey bee: Differential importance of cuticular alkanes and alkenes. Chem. Senses 30 (6), 477-89.

Downs, S.G., Ratnieks, F.L.W. (2000) Adaptive shifts in honey bee (Apis mellifera L.) guarding behavior support predictions of the acceptance threshold model. Behav. Ecol. 11, 326-333

El-Sayed, A.M. (2014) The Pherobase: Database of Insect Pheromones and Semiochemicals. http://www. pherobase.com

Ferreira-Caliman, M.J., Nascimento, F.S., Turatti, I.C., Mateus, S., Lopes, N.P., Zucchi, R. (2010) The cuticular hydrocarbons profiles in the stingless bee Melipona marginata reflect task-related differences. J. Insect Physiol. 56, 800-804

Gibbs, A., Pomonis, J.G. (1995) Physical properties of insect cuticular hydrocarbons: Model mixtures and lipid interactions. Comp. Biochem. Physiol. B 12, 667-672

Grosso, A.F., Bego, L.R. (2002) Labor division, average life span, survival curve, and nest architecture of Tetragonisca angustula angustula (Hymenoptera, Apinae, Meliponini). Sociobiology 40, 615-637

Grüter, C., Kärcher, M., Ratnieks, F.L.W. (2011) The natural history of nest defence in a stingless bee, Tetragonisca angustula (Latreille) (Hymenoptera: Apidae), with two distinct types of entrance guards. Neotrop. Entomol. 40, 55-61

Grüter, C., Menezes, C., Imperatriz-Fonseca, V.L., Ratnieks, F.L.W. (2012) A morphologically specialized soldier caste improves colony defence in a Neotropical eusocial bee. Proc. Nat. Acad. Sci. USA 109, 1182-1186

Guerrieri, F.J., Nehring, V., Jorgensen, C.G., Nielsen, J., Galizia, C.G., d'Ettorre, P. (2009) Ants recognize foes and not friends. Proc. Royal Soc. B 276, 2461-2468
Hammel, B., Vollet-Neto, A., Menezes, C., Nascimento, F.S., Engels, W., Grüter, C. (2016) Soldiers in a stingless bee: work rate and task repertoire suggest they are an elite force. Am. Nat. 187 (1), 120-129

Hothorn, T., Bretz, F., Westfall, P., Heiberger, R.M. (2008) Multcomp: Simultaneous Inference in General Parametric Models. R package version 1.0-0. Vienna: R Foundation for Statistical Computing

Howard, R.W., Blomquist, G.J. (2005) Ecological, behavioral, and biochemical aspects of insect hydrocarbons. Annu. Rev. Entomol. 50 , 371-393

Jungnickel, H., Da Costa, A.J.S., Tentschert, J., Patricio, E.F.L.R.A., Imperatriz-Fonseca, V.L., Drijfhout, F., Morgan, E.D. (2004) Chemical basis for inter-colonial aggression in the stingless bee Scaptotrigona bipunctata (Hymenoptera: Apidae). J. Insect Physiol. 50, 761-766

Kärcher, M., Ratnieks, F.L.W. (2009) Standing and hovering guards of the stingless bee Tetragonisca angustula complement each other in entrance guarding and intruder recognition. J. Apic. Res. 48, 209-214

Kather, R., Drijfhout, F.P., Martin, S.J. (2011). Task group differences in cuticular lipids in the honey bee Apis mellifera. J. Chem. Ecol. 37 (2), 205-12

Kelber, A., Zeil, J. (1997) Tetragonisca guard bees interpret expanding and contracting patterns as unintended displacement in space. J. Comp. Physiol A 181, 257-265

Leonhardt, S.D., Blüthgen, N., Schmitt, T. (2009) Smelling like resin: terpenoids account for species-specific cuticular profiles in Southeast-Asian stingless bees. Insectes Soc. 56, 157-170

Linstrom, P., Mallard, W.G. (2005) NIST Standard Reference Database Number 69. Gaithersburg: National Institute of Standards and Technology

Lorenzi, M.C., Sledge, M.F., Laiolo, P., Sturlini, E., Turillazzi, S. (2004) Cuticular hydrocarbon dynamics in young adult Polistes dominulus (Hymenoptera: Vespidae) and the role of linear hydrocarbons in nestmate recognition systems. J. Insect Physiol. 50, 935-941

Martin, S., Drijfhout, F. (2009) A review of ant cuticular hydrocarbons. J. Chem. Ecol. 32, 1151-1161

Michener, C.D. (1974) The social behavior of the bees. Harvard University Press, Cambridge

Michener, C.D. (2007) The bees of the world. Johns Hopkins University Press, Baltimore

Moure, J.S. (2008) Moure's bee catalogue. http://moure. cria.org.br/index

Nunes, T.M., Nascimento, F.S., Turatti, I.C., Lopes, N.P., Zucchi, R. (2008) Nestmate recognition in a stingless bee: does the similarity of chemical cues determine guard acceptance? Anim. Behav. 75, 1165-1171

Nunes, T.M., Turatti, I.C., Mateus, S., Nascimento, F.S., Lopes, N.P., Zucchi, R. (2009) Cuticular hydrocarbons in the stingless bee Schwarziana quadripunctata (Hymenoptera, Apidae, Meliponini): differences between colonies, castes and age. Genet. Mol. Res. 8, 589-595

Quinn, G.P., Keough, M.J. (2002) Experimental design and data analysis for biologists. Cambridge: Cambridge University Press. 
R Development Core Team (2016) R: A Language and Environment for Statistical Computing. R Foundation for Statistical Computing, Vienna. www.R-project.org

Roubik, D.W. (2006) Stingless bee nesting biology. Apidologie 37, 124-143

Sawaya, A.C.H.F., Cunha, I.B.S., Marcucci, M.C., de Oliveira Rodrigues, R.F., Eberlin, M.N. (2006) Brazilian propolis of Tetragonisca angustula and Apis mellifera. Apidologie 37, 398-407

Segers, F.H.I.D., Menezes, C., Vollet-Neto, A., Lambert, D., Grüter, C. (2015) Soldier production in a stingless bee depends on rearing location and nurse behaviour. Behav. Ecol. Sociobiol. 69, 613-623

van Wilgenburg, E., Sulc, R., Shea, K.J., Tsutsui, N.D. (2010) Deciphering the Chemical Basis of Nestmate Recognition. J. Chem. Ecol. 36, 751-758

van Zweden, J.S., Grüter, C., Jones, S.M., Ratnieks, F.L.W. (2011) Hovering guards of the stingless bee Tetragonisca angustula increase colony defensive perimeter as shown by intra- and inter-specific comparisons. Behav. Ecol. Sociobiol. 65, 1277-1282

Velikova, M., Bankova, V., Marcucci, M.C., Tsvetkova, I., Kujumgiev, A. (2000) Chemical composition and biological activity of propolis from Brazilian Meliponinae. Z Naturforsch C 55, 785-789

Venables, W.N., Ripley B.D. (2002) Modern Applied Statistics with R, 4th Edn. NewYork: SpringerPress

Wittman, D. (1985) Aerial defense of the nest by workers of the stingless bee Trigona (Tetragonisca) angustula . Behav. Ecol. Sociobiol. 16, 111-114

Yáñez-Ordónez, O., Trujano Ortega, M., Llorente Bousquets, J. (2008) Patrones de distribución de las especies de la tribu meliponini (Hymenoptera: Apoidea: Apidae) en México. Interciencia 33, 41-45

Zamudio, F., Alvarez, L.J. (2016) Abejas sin aguijón de Misiones: una guía etnotaxonómica para su identificación en el campo. Córdoba, Ed UNC 